\title{
LANDSLIDES MONITORING WITH TIME SERIES OF SENTINEL-1 IMAGERY IN YEN BAI PROVINCE-VIETNAM
}

\author{
V.A Tran ${ }^{1 *}$, X. Q. Truong ${ }^{2}$, D. A. Nguyen ${ }^{3}$, Laura Longoni ${ }^{4}$ V.Yordanov ${ }^{4,5}$ \\ ${ }^{1}$ Dept. of Geomatics and Land Adminnistration, HUMG, HaNoi University of Mining and Geology, No 18 Vien Street, Bac Tu \\ Liem, Hanoi, Vietnam - tranvananh@humg.edu.vn \\ ${ }^{2}$ Dept. of Information Technology, HUNRE, HaNoi University of Natural Resources and Environment, No 41 A Phu Dien Street, \\ Bac Tu Liem district, Hanoi, Vietnam - Txquang@hunre.edu.vn \\ ${ }^{3}$ Institute of Geological Sciences, Vietnam Academy of Science and Technology, No. 84 Chua Lang Street, Dong Da, Hanoi, \\ Vietnam - nguyenducanh237@gmail.com \\ ${ }^{4}$ Department of Civil and Environmental Engineering (DICA) Politecnico di Milano, Piazza Leonardo da Vinci 32, Milan, Italy- \\ (laura.longoni,vasil.yordanov)@polimi.it \\ ${ }^{5}$ Vasil Levski National Military University, Veliko Tarnovo, Bulgaria
}

KEY WORDS: Landslide, PSInSAR, Vanyen-Yenbai, Sentinel-1

\section{ABSTRACT:}

This paper presents an application of PS-InSAR method for determining landslide displacement velocity in Van Yen district, Yen Bai province, Vietnam. The used tools for processing data is a combination of two free software, SNAP 7.0 and STaMPS 4.1. With 27 Sentinel-1A images in descending direction acquired from $11^{\text {th }}$ January 2019 to $1^{\text {st }}$ March 2021, the landslide displacement values were calculated and exported. There were locations in which landslides correctly appeared, such as Lang Thip, Xuan Tam, Chau Que Ha, Phong Du Thuong communes and along provincial road 151. Landslide rate is determined from SAR image series with average value less than $16.5 \mathrm{~mm} / \mathrm{y}$ in places with high terrain and steep slope. The distribution of permanent scatter (PS) points for landslides often appeared along the road slopes, especially the inter-communal and inter-provincial roads that have not been reinforced with structural mitigation measures. In 2013 a field survey was conducted by the Vietnam Institute of Geosciences and Mineral Resources for this area which was used to validate the results from SAR processing. Landslide velocity charts at certain landslide sites were derived. The current study demonstrated the feasibility of the method as well as the usage of Sentinel-1 data for land deformation monitoring in the mountainous area.

\section{INTRODUCTION}

Vietnam is one of the countries in the region that is frequently affected by landslides due to tropical monsoon climate and three-fourths of Vietnam land area is hilly. In the context of global climate change happening quite acute, landslides are becoming more dangerous and more severe. According to research by (Quoc Hung et al., 2017) almost every year in Vietnam during the rainy season landslides occur, causing great damage to people and properties.

From the early years of the twenty-first century, scientists around the world have studied the problem of landslides and published many valuable papers on this field. Many works have used remote sensing data to detect landslide regions, tectonic destruction zones, etc., In the remote sensing field, the SAR satellite interferometric measurement is a method applied for evaluating changes on the Earth's surface proved very useful. Differential SAR Interferometry (DInSAR) is a method used to detect land deformations by using two or more images of the same location acquired at different times, usually before and after a topographic change occurs (Anh et al., 2007). However, this method has many limitations such as the influence of the atmosphere and some scattering characteristics of objects on the surface. The PSI method proposed by (Ferretti et al., 2001), is based on using a series of multi-temporal SAR images of the same location to extract the permanent scattering points which are used for detecting terrain deformation.

PSInSAR method has been applied to monitor landslides by (Colesanti et al., 2003),(Colesanti and Wasowski, 2006), (Bozzano et al., 2017). In particular, the existence of free SAR images in the archives as well as new acquisitions gives
PSInSAR the ability to measure and monitor the terrain changes in the past and present.

There have been many landslide studies in Vietnam, including a study on landslides in Hoa Binh Hydropower (Hung and Tung, 2015). Another research about predicting the risk of landslide in mountainous areas, North Vietnam and solutions for prevention by Dieu Tien Bui (Bui et al., 2017). Recently, the research of (Van Tran et al., 2020) used ALOS PalSAR images with Small Baseline (SBAS) method for detecting landslides in Laocai province.

In our research, the PSInSAR method was used for landslide determination in the Van Yen district, Yenbai province of Vietnam using the Sentinel-1 time series images.

\section{METHODOLOGY}

The use of radar interferometry (InSAR) technique to monitor the surface of the Earth, including the topographic surfaces and the terrain deformation, has been successfully demonstrated over the past two decades. The traditional interferometric method allows the creation of interferogram images of the phase shifts between two or three images acquired at different times over the same area on the surface. Equation (1) illustrates the phase of land deformation (Zebker et al, 1986).

Assuming that if a DEM of the imaged scene is available, $\varphi_{\text {Topo }}$ can be simulated and subtracted from $\Delta \varphi_{\text {Int }}$ (this is the inverse operation performed in InSAR DEM generation), obtaining the so-called DInSAR phase $\Delta \varphi_{\text {D-Int }}$ : 
$\Delta \varphi_{D-\text { Int }}=\Delta \varphi_{\text {Int }}-\varphi_{\text {Toposstimu }}=\varphi_{\text {Displ }}+\varphi_{\text {Topo_res }}+$

$\varphi_{\text {Atm_s }}-\varphi_{\text {Atm_M }}+\varphi_{\text {Orb_s }_{-}}-\varphi_{\text {Orb_M }_{-}}+\varphi_{\text {Noise }}+2 . k . \pi$

where

$\phi_{\text {Toposimu }}=$ simulated topographic component,

$\varphi_{\text {Topo }_{\text {res }}}=$ the residual topographic error (RTE) component, $\varphi \mathrm{Atm}=$ the atmospheric phase component at the time of acquisition of each image.

$\varphi_{\text {Orb }}=$ the phase component due to the orbital errors of each image

$\varphi_{\text {Noise }}=$ the phase noise.

$\mathrm{k}=$ an integer value called phase ambiguity

The goal of DInSAR technique is to derive $\varphi_{\text {Displ }}$ from $\Delta \varphi_{D}$ Int This implies separating $\varphi_{\text {Displ }}$ from the other phase components of Eq. (1). An essential condition to accomplish this separation is to analyse pixels characterized by small $\varphi_{\text {Noise }}$, which are typically related to two types of reflectors: those where the response to the radar is dominated by a strong reflecting object and is constant over time (Permanent Scatterer, PS) and those where the response is constant over time but is due to different small scattering objects (Distributed Scatterers, DS). PSI represents a specific class of DInSAR techniques, which exploits multiple SAR images acquired over the same area, and appropriate data processing and analysis procedures to separate $\varphi_{\text {Displ }}$ from the other phase components depicted in Eq. (1). For more information on PSInSAR refer to Ferreti's documentation (Ferretti et al., 2001).

\section{STUDY AREA AND DATA USED}

\subsection{Study area}

The study area is Van Yen district which is the largest district in Yen Bai province, Vietnam. There is provincial road 151 and the Hanoi - Lao Cai railway line running along the area connecting Tran Yen district with Lao Cai province.

Van Yen has a very rich system of rivers, streams, ponds and lakes. The Red River originates from Yunnan (China), the length flowing through Van Yen is $70 \mathrm{~km}$ long. The tributaries of the Red River in the district have up to 40 streams flowing into the Red River. The largest of which are Thia and Hut streams flowing from Van Chan district through the district with a total length of more than $100 \mathrm{~km}$.

The topography of Van Yen is mainly in the form of medium to high mountains, originating from corrasion and denudation, the elevation difference is from $200 \mathrm{~m}$ to $1700 \mathrm{~m}$, gradually lower to the southeast. The whole Van Yen district is like "a mountain trough" that extends from the northwest to the southeast, in the middle is the Red River valley. This area has a natural slope from $20^{\circ}$ to $40^{\circ}$ with a network of many streams, narrow steep valleys and is strongly dissected. This is one of the very important factors causing landslides and other disasters in this district (Figure 1).

The study area has a very complex geological structure, neotectonic activities develop strongly, with the major fault being the deep fault of the Red River which forms a fault system that develops in the northwest - southeast. These fault systems have strongly changed the structure of the bedrock, creating many tectonic rupture zones, which are very favourable conditions for occurring of geological disasters. Through field survey, it was found that Provincial Road 151 running through almost coincides with the faults of the Red River. Combined with the process of sawing the slopes to make roads, many landslides occurred on Provincial Road 151 and that is the cause for greatly affecting the life, economy - society of people in Van Yen district.

As reported by Le Quoc Hung (Quoc Hung et al., 2017), the phenomenon of landslides and geological disasters in this area often occurs in the rainy season from June to October every year. Landslides often occur on talus cliffs or mountain slopes with human impact such as cutting slopes to make roads. At present, landslides happen in many and densely along the road section 151 through Dong An, Chau Que Ha, Dong Cuong, Lam Gang communes. (Figure 2). In addition, there are large-scale landslides on the mountains due to tectonic activities. Figure 2 shows the survey location of landslide sites, last updated in 2013.



Figure 1. The red rectangle is the Sentinel-1 frame of the Yenbai area on the map of Vietnam, The yellow rectangle is the frame of Van Yen district.

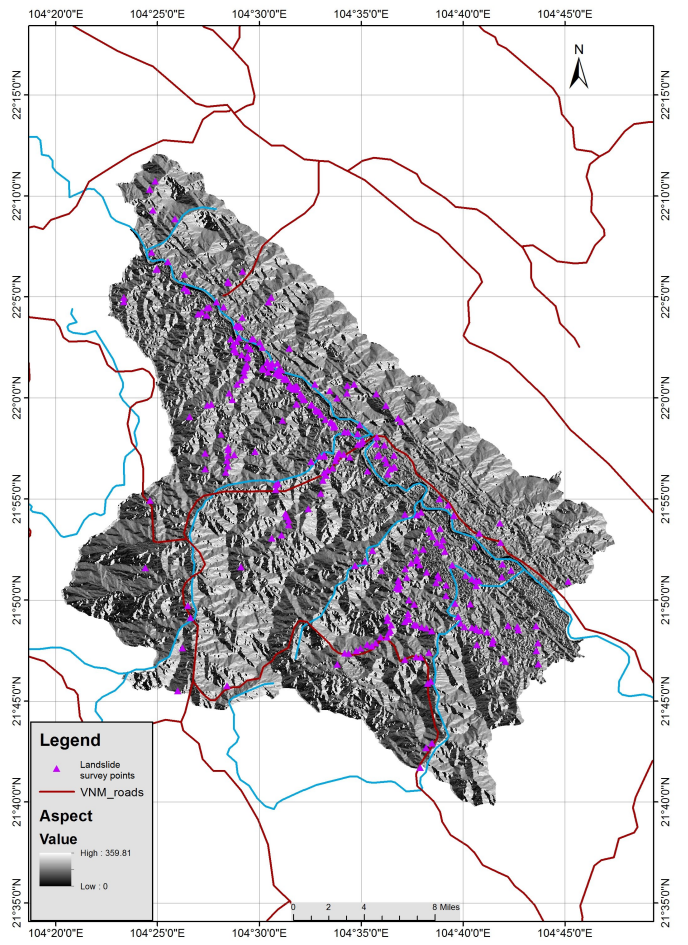

Figure 2. Landslide survey points last updated in 2013 superimposed with aspect map. 


\subsection{Data}

In this study, 27 descending Sentinel-1A (Terrain Observation with Progressive Scans SAR)-TOPSAR images, $\mathrm{C}$ band and $(\mathrm{VV}+\mathrm{VH})$ polarization acquired from $11^{\text {th }}$ January 2019 to 1 st March 2021 were used. Sentinel-1A are free accessibility at Alaska Satellite Facility archives (ASF) with regularly repeated acquisition at a 12-day interval (https://asf.alaska.edu/).

Details of the Sentinel-1A data used in the study including the date of acquisitions and the perpendicular baseline are shown in Table 1. All pairs of SAR images were checked for concordance by selecting a perpendicular baseline of less than $200 \mathrm{~m}$ (Tzouvaras et al., 2020).

\begin{tabular}{|c|c|c|}
\hline Image order & $\begin{array}{c}\text { Acquired } \\
\text { data }(\mathrm{D} / \mathrm{M} / \mathrm{Y})\end{array}$ & $\begin{array}{c}\text { Perpendicular } \\
\text { baseline (m) }\end{array}$ \\
\hline 1 & 11-Jan-2019 & 74 \\
\hline 2 & 16-Feb-2019 & 46 \\
\hline 3 & 12-Mar-2019 & 51 \\
\hline 4 & 5-Apr-2019 & 69 \\
\hline 5 & 11-May-2019 & 17 \\
\hline 6 & 15-Aug-2019 & 19 \\
\hline 7 & 08-Sep-2019 & 50 \\
\hline 8 & 26-Oct-2019 & 114 \\
\hline 9 & 07-Nov-2019 & 55 \\
\hline 10 & 13-Dec-2019 & 7 \\
\hline 11 & 18-Jan-2020 & 90 \\
\hline 12 & 11-Feb-2020 & 7 \\
\hline 13 & $23-F e b-2020$ & 14 \\
\hline 14 & 18-Mar-2020 & 0 \\
\hline 15 & 11-Apr-2020 & 71 \\
\hline 16 & 5-May-2020 & 39 \\
\hline 17 & 10-Jun-2020 & 82 \\
\hline 18 & 22-Jul-2020 & 11 \\
\hline 19 & 16-Jul-2020 & 76 \\
\hline 20 & 9-Aug-2020 & 36 \\
\hline 21 & 21- Aug -2020 & 64 \\
\hline 22 & 14-Sep-2020 & 42 \\
\hline 23 & 8 -Oct-2020 & 12 \\
\hline 24 & 20- Oct -2020 & 62 \\
\hline 25 & 1-Nov-2020 & 15 \\
\hline 26 & 17-Feb-2021 & 114 \\
\hline 27 & 1-Mar-2021 & 43 \\
\hline
\end{tabular}

Table 1. Sentinel-1A dataset and Perpendicular Baseline data showing the perpendicular distances between slave images and the master image were selected as of March 18, 2020.

\section{IMAGE PROCESSING}

With the Sentinel-1 dataset, the data processing for PSInSAR method will be divided into two main parts (Foumelis et al., 2018): (I) DInSAR processing for the master image and preparation of the slave images for interferogram generation using SNAP software (ESA SNAP), and (II) PSInSAR processing using StaMPS (Hooper et al., 2012). Figure 3 is a flow chart of PSInSAR data processing using SNAP and StaMPS. Details of these steps will be described in the following sections. Figure 4 shows the temporal and perpendicular baseline of data set, in which the central position is the master image and the surrounding positions are the slave images.

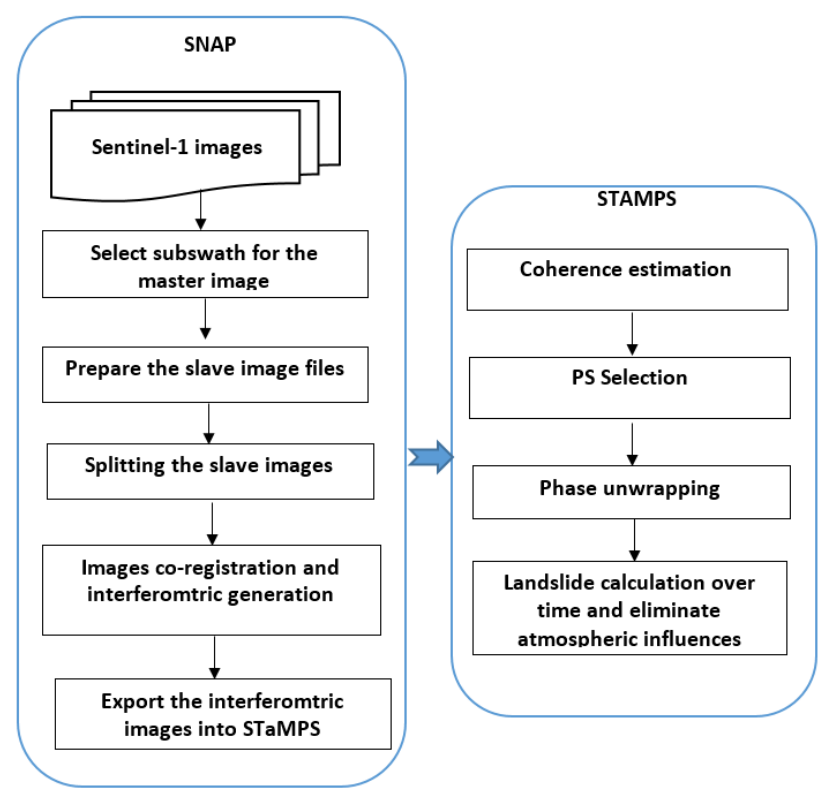

Figure 3. PSInSAR data processing flow chart using SNAP and StaMPS.

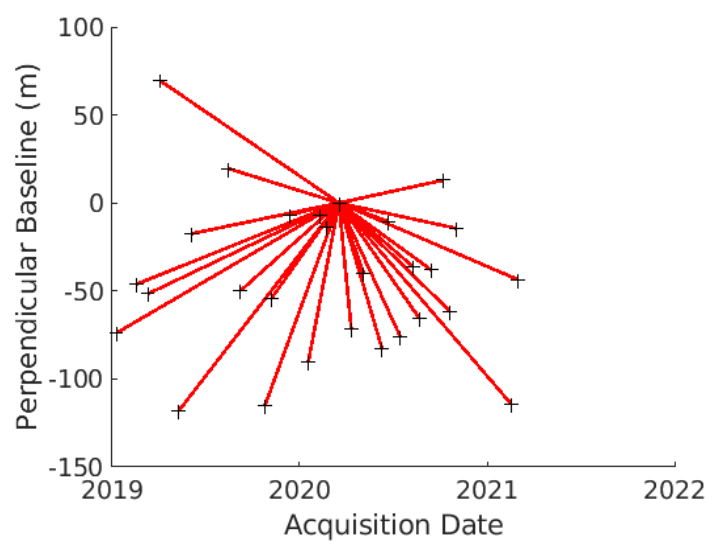

Figure 4. Temporal and perpendicular baseline of data set.

\subsection{Select the sub-swath for master image}

After selecting the main image from the dataset in SNAP software, this image will be extracted to a sub-region containing the study area because Sentinel-1 image has 3 sub-swaths in the vertical direction and 9 bursts in the horizontal direction. This 
selection is run automatically using the Graph Builder function in SNAP. This step is quite important because it reduces the time and memory for the rest of the processing (Delgado Blasco et al., 2019). For the Van Yen study area, the IW1 scan was selected.

\subsection{Slave image files preparation}

Except for the image selected as master image, the remaining images in the Sentinel-1 data set will be sorted in the order of the date of image acquisition and included as slave images. From this processing step, batch mode processing is possible, the graph processing tool (GPT) is used, the code to run the processing in XML format is available on Github and runs on Python 2.7 (Foumelis et al., 2018).

\subsection{Spliting the slave images}

The slave images are also depolarized as VV is similar to master image. During further processing, master and slave images are automatically subsetted according to the defined the area of interest (AOI). The slave image orbital information are then updated by automatically downloading the correct orbital vectors from the ESA web site (https://qc.sentinel1.eo.esa.int)

\subsection{Image co-registration and interferometric generation}

This step is computationally demanding, since the master image and each slave image, previously prepared, are co-registered. Next, interferogram for each pair of images is generated and the flat earth phase is removed (the phase relative to the ellipsoid). Debursting all the SLC images is necessary for removing the horizontal stripes. The terrain phase is simulated and eliminated using the SRTM Digital Terrain Model (DTM), which is automatically downloaded by SNAP. In this step, the study area will be subset.

\subsection{Export the interferometric images into STaMPS}

Exporting the data will produce three folders: first containing single look complex images (SLC) of all image, second containing the interferometric pairs of the master image and the slave images and the last folder is containing the coordinates of the master image and the digital elevation model (DEM) of the study area.

\subsection{PS selection}

After exporting the data from SNAP, it needs a preparatory step before importing it into STaMPS. This preparation helps for the selection of permanent scattering points (PSs) of the time series images. The threshold for PSs point taken depends on the amplitude dispersion $\mathrm{D}_{\mathrm{A}}$ that is shown as:

$$
D_{A}=\frac{\partial_{A}}{m_{A}}
$$

where $\partial_{\mathrm{A}}$ is the standard deviation and $\mathrm{m}_{\mathrm{A}}$ is the mean of the backscattering intensity. The main part of the PSInSAR calculation in STaMPS is done in Matlab. The selection of PS points of the images are done according to the $D_{A}$ value set from the previous step, then the image pair coherence is calculated and selected the PSs (Hooper et al., 2010).

\subsection{Phase unwrapping}

The interferometric phase of image pair after calculation is the wrap phase which varies from $-\pi$ to $\pi$ and is called ambiguity. Phase unwrapping is used to remove ambiguity in order to get real phase. Phase unwrapping is the most challenging step and also it could influence the accuracy of the results. StaMPS has the phase unwrapping methods as the "Minimum Cost flow 2D
(MCF)" algorithm, or the MCF 3D method (Hooper et al., 2010). The MCF 3D method was chosen for the phase unwrapping of our dataset because it proved highly accurate (Hooper et al., 2010).

\subsection{Landslides calculation over time and eliminate atmospheric influence}

In this step, spatially-correlated look angle (SCLA) error is computed which is due to almost exclusively to spatiallycorrelated DEM error. The master atmosphere and orbit error (AOE) phase is estimated simultaneously (Hooper et al., 2010).

\section{RESULTS AND DISCUSSION}

With the dataset downloaded and using the SNAP and StaMPS software, it was obtained 54666 permanent scattering points (PSs) in the study area. After phase unwrapping and atmospheric influence removed, the displacement value in the light of sight (LOS) was calculated and exported to shape file. This result is superimposed on the topographic map including roads and river system (Figure 5). The map shows an average annual landslide of Van Yen district from January 11, 2019 to March 1, 2021, the highest deformation of $-16.6 \mathrm{~mm} / \mathrm{y}$ shown in red. Based on the distribution of PS points, the points with a relatively high rate of displacement LOS (VLOS $>5 \mathrm{~mm} /$ year) for the entire study area were selected including Lang Thip, Chau Que Ha, Xuan Tam, Phong Du Thuong, Na Hau and the area along provincial road 151. (Figure 5)

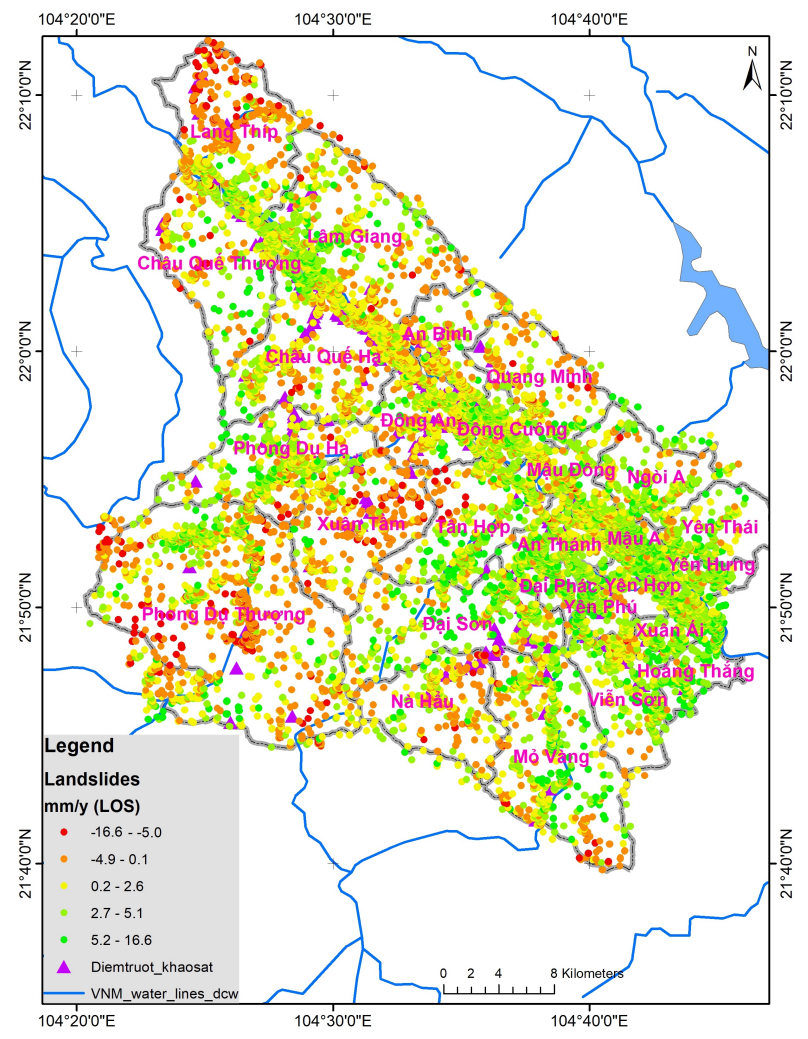

Figure 5. Landslides in Van Yen, Yenbai Province; the violet triangle are the landslides survey points (Quoc Hung et al., 2017).

Landslides survey points collected in 2013 by Vietnam Institute of Geosciences and Mineral resources (Quoc Hung et al., 2017) were mapped and compared with some positions of landslide points analysed from the radar images (PSs). There were some 
spots that are quite similar to the surveying results. The areas with dense PS points will be investigated in more detail below are the communes of Lang Thip, Chau Que Ha, Xuan Tam, Phong Du Thuong and the area along provincial road 151.

\subsection{Lang Thip commune landslide}

Lang Thip commune has a rather complicated topography, mountains with an average height between $900 \mathrm{~m}$ and $1100 \mathrm{~m}$. The PS points are distributed mainly on steep slopes along inter-commune roads. The time series for Sentinel-1 data from January 11, 2019 to March 1, 2021 (Figure 6) is not smooth and shows the displacement rate in the LOS direction of PS points in this area of average $-15.4 \mathrm{~mm} /$ year. In the region, there are not landslide survey points during this time period except for the survey data from 2013 mentioned above. Based on the field survey points overlaid on the landslide map from SAR analysis, the field survey point with the higher deformation value inside area A (YB120252.L2) was selected and graphed. The graph shows land deformation in the time from January 11, 2019 to March 1, 2021 (Figure 6).



Figure 6. (a) Distribution of permanent scatter points showing landslide rate, (b) the positions of PS points matched with survey point in Lang Thip commune are superimposed on aspect map, (c) the chart of landslide point selected from (b).

\subsection{Chau Que Ha commune landslide}

In the Chau Que Ha area, PS points are concentrated in 3 clusters, these points also have medium to small landslide velocty, and the average landslide rate is less than $-10 \mathrm{~mm} / \mathrm{y}$. In this area, the landslide survey points are not very matching, in two clusters of high deformation, there are no survey points. At a survey site inside ellipse B with code YB120583.L2 is matched with PS point. This point has been charted by time series (Figure 7). The variation of the soil deformation values is quite coarse, which ranges from $+20 \mathrm{~mm}$ to $-20 \mathrm{~mm}$.

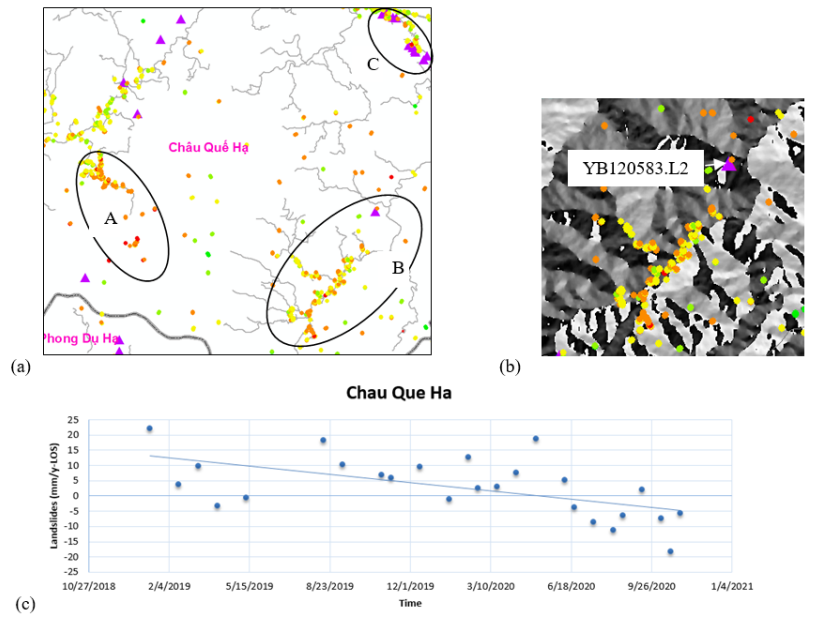

Figure 7. (a) Distribution of permanent scatter points showing landslide rate, (b) the positions of PS points matched with survey point in Chau Que Ha commune are superimposed on aspect map, (c) the chart of landslide point selected from (b).

\subsection{Xuan Tam commune landslide}

Similar to the Chau Que Ha, clusters of PS points appear quite a lot on slopes with slopes from 15 to $20 \%$, PS points have a landslide rate of less than $10 \mathrm{~mm} / \mathrm{y}$ in the LOS direction (Figure 8). In this commune, there are four clusters of deformation points clustered in four ellipses. In these four clusters, the field survey points also do not coincide with the PS points but shift with each other. In ellipse $\mathrm{C}$, a point has been taken close to the survey point with code YB120491.L2 The displacement velocity graph is reported in Figure 8c.
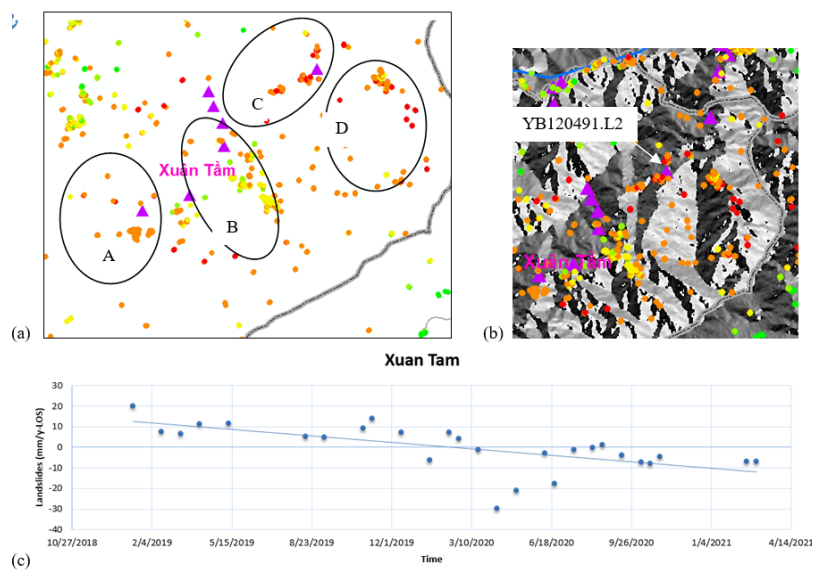

Figure 8. (a) Distribution of permanent scatter points showing landslide rate, (b) the positions of PS points matched with survey point in Xuan Tam commune are superimposed on aspect map, (c) the chart of landslide point selected from (b)

\subsection{Phong Du Thuong commune landslide}

Phong Du Thuong is located in the southwest of Van Yen, this area has an average altitude of $200 \mathrm{~m}$ to $1500 \mathrm{~m}$. The distribution of PS points here is quite concentrated in an area along the inter-commune road and the streams. The location with many PS points has been highlighted by the ellipse. Unfortunately, there is almost no field survey in this area, except for a single point, but it does not coincide with any PS point.

Because the PS points showing the magnitude of landslides appear to be the highest in Van Yen district, a location within 
the circle in Figure 9b were selected for charting and the graph is shown in Figure 9c. The graph shows landslide values over time from January 2019 to March 2021 which are $+40 \mathrm{~mm}$ to $40 \mathrm{~mm}$.

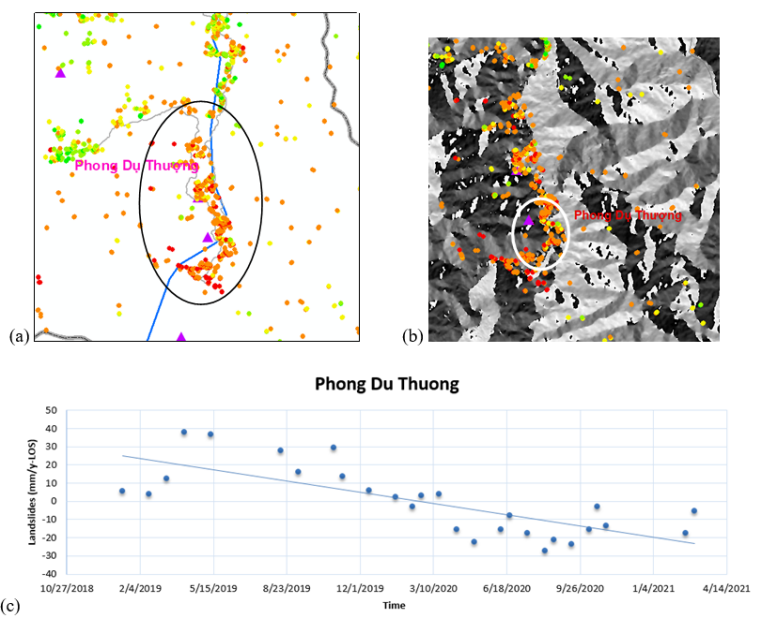

Figure 9. (a) Distribution of permanent scatter points showing landslide rate, (b) the positions of PS points matched with survey point in Phong Du Thuong commune are superimposed on aspect map, (c) the chart of landslide point selected from (b).

\subsection{Na Hau commune landslide}

In the $\mathrm{Na} \mathrm{Hau}$, deformation values are small below $10 \mathrm{~mm} /$ year, concentrated in the road connecting Dai Son commune to the centre of $\mathrm{Na} \mathrm{Hau}$ commune. In the area illustrated by two ellipses $\mathrm{A}$ and $\mathrm{B}$, the average landslide rate are less than $10 \mathrm{~mm} / \mathrm{y}$ and $13 \mathrm{~mm} / \mathrm{y}$ at $A$ and $B$ location, respectively. In ellipse $B$, there is one field survey point with code YB160197.L2 that coincides with some PS points and it is used to report the velocity chart shown in Figure 10c.
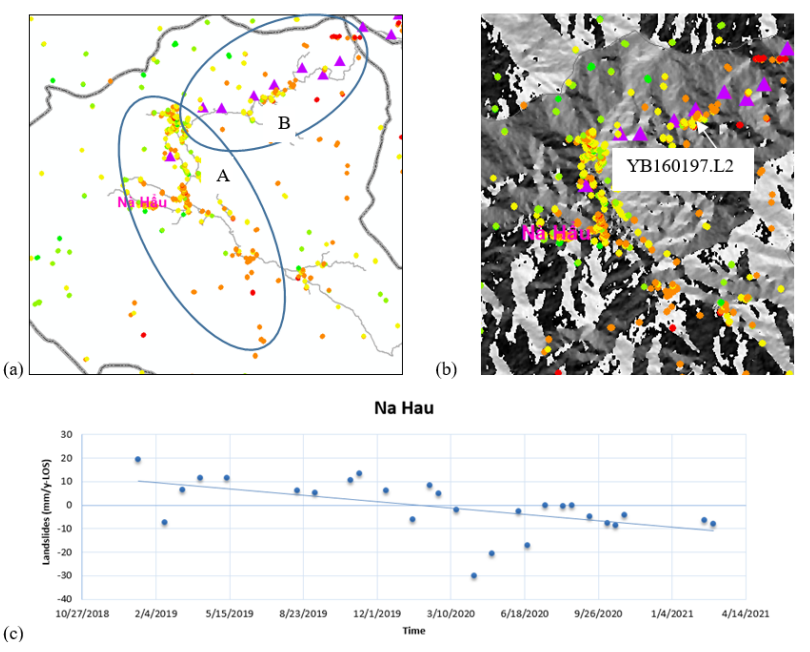

Figure 10. (a) Distribution of permanent scatter points showing landslide rate, (b) the positions of PS points matched with survey point in $\mathrm{Na}$ Hau commune are superimposed on aspect map, (c) the chart of landslide point selected from (b).

\subsection{Along provincial road 151 landslide}

For the area along Provincial Road 151, the terrain is not characterised with high altitudes, with an average elevation of less than $200 \mathrm{~m}$. Numerous PS points appear, but all values show small deformation, most of the average land deformation values are less than $5 \mathrm{~mm}$ /year except for a few higher values which are matched with the field survey points from 2013. They those are located at Chau Que Ha, Lam Giang, Dong An with assigned code numbers YB120336.L2, YB120614.L2, YB120558.L2. From these locations, a point in Lam Giang commune was selected to plot the deformation over time and the results are shown in Figure 11c.


Figure 11. Distribution of permanent scatter points showing landslide rate, (b) the positions of PS points matched with survey point along the 151 road are superimposed on aspect map, (c) the chart of landslide point selected from (b).

When interpreting landslide maps of the study area based on SAR Sentinel-1 data, it is important to note that not all slopes are visible by SAR due to the way of the image acquisition causes shadow and layover. In addition, the exposure of the landslide slopes is also important because the motion of the scattering points in the direction close to the satellite track of the satellite can hardly be corrected by the SAR interferometer (Kiseleva et al., 2014). This explains the fact that there are many locations where the landslide occurred but could not be identified by radar images. In addition, dense vegetation also limits the backscattering of radar waves, so it is difficult for areas with dense forests like Xuan Tam, Chau Que Ha.

\section{CONCLUSION}

The use of multi-temporal Radar satellite imagery with PSInSAR method helps to better understand and model the progress of landslides. In addition, based on the time-series of Sentinel-1 data the landslide velocity can be generally calculate at certain times even for very small deformations ( $\mathrm{mm} /$ year).

However, this method also has some restrictions since they heavily depend on the choice of satellite orbits are suitable to the area. For some locations landslides can be identified in an ascending direction however in a descending direction it is not possible. Therefore, land deformations can be more accurately determined if both ascending and descending images are processed.

For areas covered with dense vegetation there are no permanent scatter points (PS) that can be monitored at various times or another issue could be the size of the PS points not being large enough, making this method hard to apply. To overcome the problem, artificial scattering points should be installed in the study area, which will act as PS points and the reflected signal for the points would be very good. 


\section{ACKNOWLEDGMENT}

This work is supported by the Bilateral Scientific Research project between Vietnam and Italy, code: NĐT/IT/21/14 funded by Ministry of Science and Technology of Vietnam (MOST) and Funded by a grant from the Italian Ministry of Foreign Affairs and International Cooperation.

\section{REFERENCES}

Anh TV, Masumoto S, Raghavan V, Shiono K, 2007: Spatial distribution of subsidence in Hanoi detected by JERS-1 SAR interferometry. Japan Society of Geoinformatics 18 (1), 3-13. doi.org/10.6010/geoinformatics.18.3.

Bozzano F, Mazzanti P, Perissin D, Rocca A, De Pari P, Discenza ME, 2017: Basin scale assessment of landslides geomorphological setting by advanced InSAR analysis. Remote Sensing 9 (3), 267-286. doi.org/10.3390/rs9030267.

Bui DT, Nguyen QP, Hoang N-D, Klempe H, 2017: A novel fuzzy K-nearest neighbor inference model with differential evolution for spatial prediction of rainfall-induced shallow landslides in a tropical hilly area using GIS. Landslides 14 (1), 1-17. doi.org/10.1007/s10346-016-0708-4.

Colesanti C, Ferretti A, Prati C, Rocca F, 2003: Monitoring landslides and tectonic motions with the Permanent Scatterers Technique. Engineering geology 68 (1-2), 3-14. doi.org/10.1016/S0013-7952(02)00195-3.

Colesanti C, Wasowski J, 2006: Investigating landslides with space-borne Synthetic Aperture Radar (SAR) interferometry. $\begin{array}{llll}\text { Engineering geology } 88 & \text { (3-4), } & 173-199 .\end{array}$ doi.org/10.1016/j.enggeo.2006.09.013.

Delgado Blasco JM, Foumelis M, Stewart C, Hooper A, 2019: Measuring Urban Subsidence in the Rome Metropolitan Area (Italy) with Sentinel-1 SNAP-StaMPS Persistent Scatterer Interferometry. Remote Sensing $11 \quad$ (2), 129. doi.org/10.3390/rs11020129.

Ferretti A, Prati C, Rocca F, 2001: Permanent scatterers in SAR interferometry. IEEE Transactions on geoscience and remote sensing 39 (1), 8-20. DOI: 10.1109/36.898661.

Foumelis M, Blasco JMD, Desnos Y-L, Engdahl M, Fernández D, Veci L, Lu J, Wong C, 2018: ESA SNAP-StaMPS Integrated
Processing for Sentinel-1 Persistent Scatterer Interferometry. IGARSS 2018-2018 IEEE International Geoscience and Remote Sensing Symposium, 1364-1367. DOI: 10.1109/IGARSS.2018.8519545.

Hooper A, Bekaert DPS, Spaans K, Arıkan M, 2012: Recent advances in SAR interferometry time series analysis for measuring crustal deformation. Tectonophysics 514-517, 1-13. doi:10.1016/j.tecto.2011.10.013.

Hooper A, Spaans K, Bekaert D, Cuenca MC, Arıkan M, Oyen A, 2010: StaMPS/MTI manual. Delft Institute of Earth Observation and Space Systems Delft University of Technology, Kluyverweg 1:2629.

Hung BK, Tung DM, 2015: About the Damage of the Penstock of Xekaman 3 Hydropower Plant Due to Sliding and the Remedial Measures for Power Generation. In: ISRM VietRock International Workshop,. International Society for Rock Mechanics and Rock Engineering.

Kiseleva E, Mikhailov V, Smolyaninova E, Dmitriev P, Golubev V, Timoshkina E, Hooper A, Samiei-Esfahany S, Hanssen R, 2014: PS-InSAR monitoring of landslide activity in the Black Sea coast of the Caucasus. Procedia Technology 16, 404-413. doi.org/10.1016/j.protcy.2014.10.106.

Quoc Hung L, Van NTH, Van Son P, Ninh NH, Tam N, Huyen NT, 2017: Landslide inventory mapping in the fourteen northern provinces of Vietnam: achievements and difficulties. In: Workshop on World Landslide Forum. Springer Nature, Cham 501-510. doi.org/10.1007/978-3-319-59469-9_44.

Tzouvaras M, Danezis C, Hadjimitsis DG, 2020: Small scale landslide detection using Sentinel-1 interferometric SAR coherence. Remote Sensing 12 (10):1560. doi.org/10.3390/rs12101560.

Van Tran A, Nguyen BA, Dinh T, Nguyen YHT, Le NT, 2020: Landslides detection in Bat Xat district, Lao Cai province, Vietnam using the Alos PalSAR time-series imagery by the SBAS method. Journal of Mining and Earth Sciences 61 (4),110. DOI:10.46326/JMES.2020.61(4).01. 